\title{
Experimental investigation on the behavior of glued-in rod joints in timber beams subjected to monotonic and cyclic loading
}

\author{
Natalino Gattesco $^{\mathrm{a}}$, Alessandra Gubana ${ }^{\mathrm{b}}$, Manuela Buttazzi ${ }^{\mathrm{b}}$, Massimo Melotto ${ }^{\mathrm{c}, *}$ \\ ${ }^{a}$ Department of Engineering and Architecture, University of Trieste, Piazzale Europa 1, 34127 Trieste (TS), Italy \\ ${ }^{\mathrm{b}}$ Polytechnical Department of Engineering and Architecture, University of Udine, via delle Scienze 206, 33100 Udine (UD), Italy \\ ${ }^{\mathrm{c}}$ Department of Civil, Environmental, Architectural Engineering and Mathematics, University of Brescia, via Branze 43, 25123 Brescia (BS), Italy
}

\section{A R T I C L E I N F O}

\section{Article history:}

Received 22 June 2016

Revised 14 March 2017

Accepted 16 March 2017

Available online 14 June 2017

\section{Keywords:}

Glued-in rod connections

Moment joints

Cyclic tests

Timber constructions

\begin{abstract}
A B S T R A C T
Glued-in rod connections for timber beams are increasingly being used, as they offer high strength and stiffness and a better appearance in comparison with traditional mechanical connections. First, a campaign of experimental tests on glued-in threaded steel rod joints subjected to monotonic bending moments was carried out, checking the effect of a confining system for the bars (transversal screws) and the different arrangement of the rods, or varying the mechanical characteristics of the steel of the bars. A negligible effect on joint ductility was observed using transversal screws whereas with a correct design and a proper choice of rod steel grade an important ductile behavior was achieved. The experiments were then extended to cyclic tests so to emphasize the cyclic performance of glued-in rod joints under bending moments. The aim was mainly to understand the joint structural response under cyclic loads, simulating the effects of seismic action. The test results indicate that the joint can initially develop a high dissipative capacity, but after a few cycles, the energy dissipation is considerably reduced by the occurrence of longitudinal splitting in the timber edge of the joining bars leading to lateral instability of the rods.
\end{abstract}

(c) 2017 Elsevier Ltd. All rights reserved.

\section{Introduction}

Glued-in rod joints, made with steel bars placed into predrilled holes in timber members and bonded with epoxy or polyurethane resins, are increasingly being used to connect glulam beams. This type of joint, if properly designed, can offer high strength, high stiffness, more uniform stress distribution in the wood, with no stress peaks near the rods and better aesthetic appearance in comparison with traditional mechanical connections made with bolts, pins, or dowels. Moreover, the wood surrounding the steel rods preserves them from corrosion.

Despite many research studies and practical applications, a universal standard for design has not yet been achieved (Larsen [1], Steiger et al. [2]). Studies on glued joints have been performed for over 25 years by several authors, among the first Riberholt [3], Ballerini et al. [4], Buchanan and Deng [5], Aicher et al. [6] and Steiger et al. [7]. The earliest formulations used to predict the pull-out resistance of the joint were then proposed. In fact a great part of the literature about glued-in rod joints initially focused on pull-out tests, as the first aim was to investigate the

\footnotetext{
* Corresponding author.

E-mail address: m.melotto001@unibs.it (M. Melotto).
}

load-slip relationship and define the failure mechanisms. In this way, tests were carried out primarily on specimens arranged with one bar, and the investigations identified five different failure mechanisms related to a single rod connection (Steiger at al. [2]):

1. bar failure, due to material failure or rod buckling;

2. pull-out of the rod due to adhesive failure at the interfaces through cohesive failure either in the adhesive or in the wood close to the bond line;

3. pull out of the wood plug;

4. splitting of the wood due to short edge distances;

5. tensile failure in the net or gross wood cross section.

Few test data on multiple rod connections are available in the literature, and they often concern pull-out tests. Studies on groups of rods were performed by Gehri [8], Broughton and Hutchison [9], Tomasi et al. [10], Tlustochowicz et al. [11], and Parida et al. [12]. In addition to the previous failure modes, splitting failure due to a short rod distance and group pull-out is of interest for multiple rod connections.

Extensive experimental pull-out tests have also been performed by Gattesco and Gubana [13-16] and Gattesco et al. [17]. The aim was to investigate the role of steel mechanical characteristics and 
of edge distance in the joint response and consequently to identify the design criteria to reach a ductile failure. Those tests showed that it was possible to obtain ductile behavior also with edge distances of only twice the bar diameter, if the bars were made of a mild steel, with low characteristic yield strength.

As previously stated, some doubts about the reliability of this joint type still remain (Larsen [1]). A general consensus on the formulas to predict pull-out strength has not been reached to date (Stepinac et al. [18]), for different key reservations, as illustrated in Steiger et al. [2], and consequently, design recommendations for the joints are still not included in Eurocode 5 [19].

The behavior of glued in-rod joints subjected to bending moments was faced in some papers as in Buchanan and Fairweather [20], where several connections incorporating steel bars are described and tested under cyclic loads, and in Andreolli et al. [21], where the investigated joint consists of a wooden element connected to a steel stub by means of an end plate and glued-in steel rods, while Fragiacomo and Batchelar [22] presented a method of evaluating joint strength for a beam to column joint, and Yang et al. [23] a component method for calculating the joint performance.

$\mathrm{Xu}$ et al. [24] investigated beam splice joints with reduced edge distances, which showed ductile behavior under monotonic loads. Also in Buttazzi [25] some early experimental investigations were carried out to study the behavior of glued-in rod joints connecting timber elements subjected to bending moment. These results provide some useful indications on the main parameters that characterize the ductile behavior of the joints.

The results obtained in the previous tests and in literature reviews clearly evidence the need to deeply investigate how to obtain an adequate ductile behavior of glued-in rod joints subjected to bending both under monotonic and cyclic loads. Moreover, the edge/spacing distances have to be minimized so to allow arranging a sufficient number of rods to guarantee a moment resistance at least equal to $60 \%$ the actual bending capacity of the wooden timber beam.

The pull-out tests presented in Gattesco et al. [17] evidenced that it is possible to obtain a ductile behavior even with edge distances equal to $2 d$ if the yielding strength of the steel of the rods is not greater than $320 \mathrm{MPa}$. So the purpose of this study was firstly to check the behavior under monotonic loads through experimental tests on beams with a glued-in steel rod joint, arranged with an edge distance of the bars equal to $2 d$. The effect of the variation of the steel grade of the rods was analyzed and in few cases the application of transversal screws perpendicular to the rods was considered to contrast splitting. The main scope was to define the joint configuration able to guarantee a ductile behavior.

Experimental tests under cyclic loads have been also performed on samples designed as those tested monotonically that provided the best ductile performances. The aim was to study the behavior of these joints under cyclic reversible loads, and to investigate the ductility level reachable by glued-in rod connections also in this load condition.

Besides the experimental study, analytical relationships were provided for design purposes of bending joints arranged with glued-in rods, evidencing the type of failure that will be expected.

\section{Design of moment-resisting glued-in rod joints}

The design of glued-in rod joints in beams has to consider all the possible failure mechanisms that may occur in the jointed cross section of the beam: glued-in rod rupture, timber collapse in compression. The rupture of glued-in rod joint, as stated in Section 1, may occur in five possible modes. The failure mode 1 is ductile in case ductile steel is used, while the others are brittle.
Actually, the failure mode 3 ( $\left.F_{\text {group }}\right)$ occurs when the spacing among bars is little and the edge distances are large; in fact, if the edge distance is less than 2.5 times the bar diameter, the whole cross section tensile failure occurs earlier than the group tear out, as evidenced in the experimental tests presented in Section 3.

In the literature many proposals for the pull out capacity are available and summarized in Stepinac et al. [18]: the proposed relationships are based primarily on the shear strength at the adhesive/timber interface. For simplicity a constant equivalent shear strength is assumed along the anchorage length, so the capacity of a single rod joint is:

$F_{\text {pull }}=\pi \cdot d_{e q} \cdot l \cdot f_{v}$,

where $d_{e q}$ is the equivalent diameter ranging between the bar diameter $d_{b}$ and the hole diameter $d_{h}, l$ is the anchorage length and $f_{v}$ is the constant equivalent shear strength along the adhesive/timber interface. The results of the pull-out tests presented in Gattesco et al. [17], using different grade for steel rods, spruce timber elements, epoxy resin as adhesive and with an anchorage length up to 30 times the rod diameter, are predicted with good reliability with the relationship for the equivalent shear strength proposed by Aicher et al. [6]:

$f_{v}=129 \cdot d_{h}^{-0.52} \cdot \lambda^{-0.62} \cdot\left(\frac{\rho}{480}\right)^{0.45} \quad(\leqslant 8 M P a)$,

where $\lambda$ is the ratio between the anchorage length $l$ and the hole diameter $d_{h}$ and $\rho$ is the specific mass of timber in $\mathrm{kg} / \mathrm{m}^{3}$.

Blass and Laskewitz [26] proposed a correction to the relationship used to estimate pull-out capacity to consider the effect of spacing $s$ and edge distance $e$, which causes earlier failure due to longitudinal splitting $\left(F_{\text {split }}\right)$. In particular, for edge distances smaller than 2.5 times the rod diameter the failure is governed by splitting and the capacity is equal to that obtained with Eqs. (1) and (2), multiplied by the reduction factor $k_{\mathrm{s}}$ :

$k_{s}=0.15 \cdot \frac{a_{1}}{d}+0.625 \quad\left(k_{s} \leqslant 1.0\right)$,

in which $a_{1}=\min (e, s / 2)$.

The tensile failure of the timber cross section $\left(F_{\text {tens }}\right)$ is based on an effective area of timber $A_{\text {eff }}$ for each steel rod. Gehri [8] proposed values for the effective area approximately equal to 20 times the cross section of steel rod. In the Eurocode 5, Part 2 [27] it was proposed an effective area per each bar equal to a square whose side is the sum of the edge distance and half the spacing among the rods, with a maximum value equal to 6 times the bar diameter.

To assess the capacity of glued-in rod joints in beams, it is necessary to distinguish if the joint section collapse is due either to steel rod tensile failure $F_{s t}$ (mode 1 ), to rod failure according to modes $2,3,4,5, F_{u}=\min \left(F_{\text {pull }}, F_{\text {group }}, F_{\text {split }}, F_{\text {tens }}\right)$, or to crushing of timber in compression.

For the joint design the following hypotheses were assumed: plane sections remain plane after bending (Navier-Bernoulli hypothesis); the strain of the steel rod is equal to the strain in the timber at the same level (no slip), the stresses in the timber and in the steel can be computed from the strains using the stress-strain curves for timber and steel. In particular, an elasticperfectly plastic behavior was assumed for timber in compression, whereas an elastic-plastic with hardening behavior was assumed for the steel of the rods. Then, by using the equilibrium equations on the joint section, the depth of the neutral axis and the moment capacity were calculated.

In the study the cases of rectangular cross section with one or two steel rods layers are considered. Being $F_{s y}$ the yielding strength of the rods, the relationships related to the main four different conditions were determined: a) $F_{u} \leq F_{s y}$, brittle failure of glued-in rod joint (modes $2,4,5$ ), linear behavior for steel bars and for timber in 
compression; b) $F_{s y}<F_{u}<F_{s t}$, brittle failure of glued-in rod joint (modes $2,4,5$ ), lower layer of steel bars in the plastic domain, plastic behavior for timber in compression; c) $F_{u} \geq F_{s t}$, failure of steel rods (strain in lower steel rods $\varepsilon_{s}$ is equal to the ultimate uniform tensile strain $\varepsilon_{s u}$ ), plastic behavior for timber in compression; d) failure of timber in compression (top section strain in timber $\varepsilon_{w}$ is equal to the ultimate timber strain $\varepsilon_{w u}$ ). The cross section details with the strain and stress distribution are illustrated in Fig. 1a, for the linear behavior, and in Fig. 1b, for the plastic behavior. For simplicity a constant distribution of stress was assumed to consider the plastic behavior of timber in compression, with a depth $a$ for the stress block $(a=\chi(x) x)$ assessed comparing the area of the actual elastic-plastic distribution of timber compression stresses with that of the simplified constant one. A constant value of $\chi_{0}$ equal to 0.8 can be assumed as a first approximation. In Fig. 1 the parameters $b$ and $h$ represent the width and the height of the timber cross section, $d$ and $d_{1}$ represent the distance of the rod layers from the top of the section, $A_{s}$ and $A_{s 1}$ represent the area of the rods in the lower and upper layer, respectively; their ratio is $\delta=A_{s 1} / A_{s}$. $T$ and $T_{1}$ represent the tensile force acting on the lower and upper layer of rods, respectively, they are equal to the force on the single rod multiplied by the number of rods per layer; $\beta$ is the ratio between the maximum resistance due to modes $2,3,4$, 5 in the upper layer $T_{u 1}$ and that in the lower layer $T_{u}$.

With reference to Fig. 1, the equilibrium equations at ultimate limit state for the case with the collapse governed by the brittle failure modes of the glued-in rods with linear elastic steel $F_{u} \leqslant F_{s y}$, assuming linear also the behavior of timber in compression, are:

$\left\{\begin{array}{l}\frac{\sigma_{w} b x}{2}-T_{u}(1+\vartheta(x))=0 \\ T_{u}\left[\left(d-\frac{x}{3}\right)+\vartheta(x)\left(\alpha d-\frac{x}{3}\right)\right]=M_{u}\end{array}\right.$

in which $\vartheta(x)$ represents the ratio between the tensile force in the upper layer of rods and the resistance of the lower layer of rods $\left(T_{u}=n_{l} F_{u}\right) ; n_{l}$ is the number of rods in the lower layer. In the Eq. (4) $\alpha d$ is equal to the distance $d_{1}$ (Fig. 1). For cases with the collapse still governed by the brittle failure modes of the glued-in rods but with steel in the plastic branch $\left(F_{s y}<F_{u}<F_{s t}\right)$ and the timber plastic in compression, the equilibrium equations become:

$\left\{\begin{array}{l}\chi_{o} \cdot f_{c, 0} \cdot b \cdot x-T_{u}(1+\vartheta(x))=0 \\ T_{u}\left[\left(d-\frac{a}{2}\right)+\vartheta(x)\left(\alpha d-\frac{a}{2}\right)\right]=M_{u}\end{array}\right.$.

For the case with the collapse governed by the failure of the steel $\operatorname{rod}\left(F_{u} \geqslant F_{s t}\right)$ and the timber plastic in compression, the equilibrium equations are the same as in Eq. (5), simply changing $T_{u}$ with $T_{s t}$ (tensile resistance of the lower layer of steel rods). Finally, when the collapse of the section is governed by the timber failure in compression, with steel rods in the plastic branch, the equilibrium equations are:

$$
\left\{\begin{array}{c}
\chi_{0} \cdot f_{c, 0} b x-\left[f_{s y}+E_{s H}\left(\epsilon_{w u} \frac{d-x}{x}-\epsilon_{y}\right)\right] A_{s}-\left[f_{s y}+E_{s H}\left(\epsilon_{w u} \frac{\alpha d-x}{x}-\epsilon_{y}\right)\right] \delta \cdot A_{s}=0 \\
{\left[f_{s y}+E_{s H}\left(\epsilon_{w u} \frac{d-x}{x}-\epsilon_{y}\right)\right] A_{s} \cdot\left(d-\frac{a}{2}\right)-\left[f_{s y}+E_{s H}\left(\epsilon_{w u} \frac{\alpha d-x}{x}-\epsilon_{y}\right)\right] \delta \cdot A_{s}\left(\alpha d-\frac{a}{2}\right)=M_{u}}
\end{array} .\right.
$$

where $\varepsilon_{w u}$ is the ultimate strain of timber in compression parallel to the grain, $f_{s y}$ is the yielding stress of steel, $E_{s H}$ is the strain hardening modulus, while in the following $E_{S}$ is the elastic modulus.

The function $\vartheta(x)$ is derived through the strain compatibility in the joint cross section; by substituting it in Eqs. (4) and (5) the neutral axis depth and the moment capacity may be obtained. The relationships for $\vartheta(x)$ and for the position of the neutral axis corresponding to the considered cases are reported in Table 1 . For case b), two sub-cases were considered: b1) when the steel of the upper rod layer is still linear elastic, b2) when both steel layers are on the plastic branch. Other cases may occur, but they are very rare in practice, so for the sake of simplicity they are not reported in Table 1.

As already stated, the value of $\chi_{o}$ assumed as a first approximation has to be checked by comparing it with the one obtained by the following equations:

$$
\left\{\begin{array}{c}
\chi(x)=1+\frac{f_{c, 0}}{2 E_{c, 0} \bar{\varepsilon}_{s}}\left(1-\frac{d}{\chi}\right) \quad \text { cases } b_{1} \text { and } b_{2} \\
\chi(x)=1+\frac{f_{c, 0}}{2 E_{c, 0} \varepsilon_{u}}\left(1-\frac{d}{x}\right) \quad \text { case } c
\end{array}\right.
$$

where the resultant of the elasto-plastic distribution is made equal to the constant stress block. If they are different, a new value of $\chi_{o}$ has to be assumed. $E_{c, 0}$ is the elastic modulus of timber parallel to the grain, $\bar{\varepsilon}_{s}$ is defined in Table 1 .

For case d), the value of the depth of the stress block is constant and it was evaluated through the relationship:

$\chi(x)=\chi_{o}=1-\frac{f_{c, 0}}{2 E_{c, 0} \varepsilon_{w u}}$.

When the case a) occurs, the resisting moment of the joint section is obtained from Eq. (4) and the collapse mechanism corresponds to the one with the minimum strength (min ( $F_{\text {pull }}, F_{\text {group }}$, $\left.\left.F_{\text {split }}, F_{\text {tens }}\right)\right)$. Whereas, when the steel yields, but it does not reach the failure, the resisting moment corresponds to the minimum value obtained for cases $\left.b_{1}\right), b_{2}$ ) and $d$ ). Finally, when the steel failure governs the joint collapse, the resisting moment is the minimum value obtained in cases c) and d).

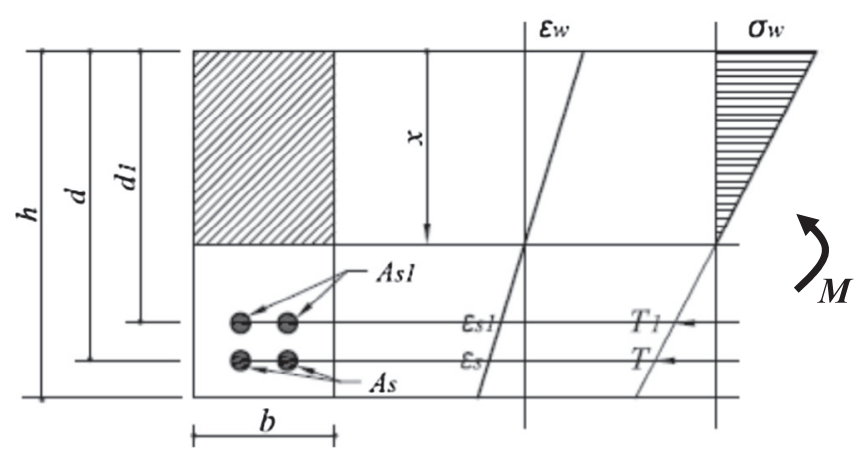

(a)

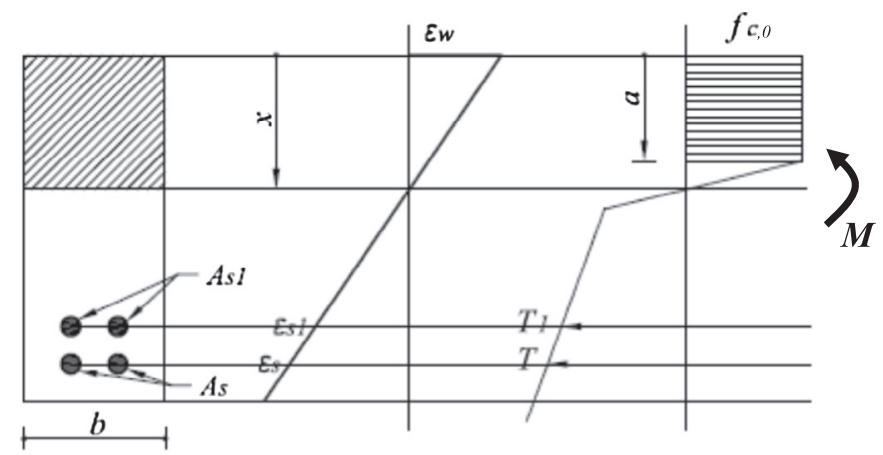

(b)

Fig. 1. Cross section details with the strain and stress distribution: a) for linear behavior, b) for plastic behavior of both timber and steel. 
Table 1

Relationships for the function $\vartheta(x)$ and the depth of the neutral axis for the considered cases.

\begin{tabular}{|c|c|c|}
\hline Case & $\vartheta(x)$ & $x$ \\
\hline a) $F_{u} \leqslant F_{s y}$ & $\beta \frac{\alpha d-x}{d-x}$ & $-n \frac{(1+\beta) A_{s}}{b}+\sqrt{\frac{(1+\beta)^{2} A_{s}^{2}}{b^{2}} n^{2}+\frac{2 n A_{s} d}{b}(1+\beta \alpha)}$ \\
\hline $\begin{array}{l}\left.\mathrm{b}_{1}\right) F_{s y}<F_{u}<F_{s t} \\
\text { lower rod layer yielded, } \\
\text { upper one linear elastic }\end{array}$ & $\begin{array}{l}\beta \frac{E_{s} \delta A_{s}}{T_{u}} \cdot \frac{\alpha d-\chi}{d-\chi} \bar{\varepsilon}_{s} \\
\bar{\varepsilon}_{s}=\left(\frac{T_{u}}{E_{s H} A_{s}}-\frac{f_{s y}}{E_{s H}}+\varepsilon_{s y}\right)\end{array}$ & $\frac{1}{2}\left[d+\frac{T_{u}}{\chi_{0} f_{c, 0} b}+\frac{\beta E_{s} \delta A_{s} \bar{\varepsilon}_{s}}{\chi_{o} f_{c, 0} b}\right]-\frac{1}{2} \sqrt{\left[d+\frac{T_{u}}{\chi_{o} f_{c, 0} b}+\frac{\beta E_{s} \delta_{s} \bar{c}_{s}}{\chi_{o} f_{c, 0} b}\right]^{2}-\frac{4 d}{\chi_{0} f_{c, 0} b}\left(T_{u}+\beta E_{s} \delta A_{s} \bar{\varepsilon}_{s} \alpha\right)}$ \\
\hline $\begin{array}{l}\left.\mathrm{b}_{2}\right) F_{s y}<F_{u}<F_{s t} \text { both rod } \\
\quad \text { layers yielded }\end{array}$ & $\begin{array}{l}\beta\left[1-\frac{E_{s H} A_{s}}{T_{u}} \bar{\varepsilon}_{S}\left(1-\frac{\alpha d-\chi}{d-\chi}\right)\right] \\
\bar{\varepsilon}_{S}=\left(\frac{T_{u}}{E_{s H} A_{s}}-\frac{f_{s y}}{E_{s H}}+\varepsilon_{s y}\right)\end{array}$ & $\frac{1}{2}\left[d+\frac{T_{u}(1+\beta)}{\chi_{0} f_{c, 0} b}\right]-\frac{1}{2} \sqrt{\left[d+\frac{T_{u}(1+\beta)}{\chi_{0} f_{c, 0} b}\right]^{2}-\frac{4 T_{u} d}{\chi_{0} f_{c, 0} b}\left[1+\beta\left(1-\frac{A_{s} E_{S H} \bar{\varepsilon}_{s}}{T_{u}}(1-\alpha)\right)\right]}$ \\
\hline $\begin{array}{l}\text { c) } F_{u} \geqslant F_{s t} \\
\text { Steel rod failure }\end{array}$ & $\delta\left[1-\frac{E_{s H} \varepsilon_{u}}{f_{s u}}\left(1-\frac{\alpha d-\chi}{d-\chi}\right)\right]$ & $\frac{1}{2}\left[d+\frac{T_{s t}(1+\delta)}{\chi_{0} f_{c, 0} b}\right]-\frac{1}{2} \sqrt{\left[d+\frac{T_{s t}(1+\delta)}{\chi_{o} f_{c, 0} b}\right]^{2}-\frac{4 T_{s t} d}{\chi_{o} f_{c, 0} b}\left[1+\delta\left(1-\frac{E_{S H} \varepsilon_{u}}{f_{s u}}(1-\alpha)\right)\right]}$ \\
\hline $\begin{array}{l}\text { d) Timber failure in } \\
\text { compression }\end{array}$ & - & $\frac{A_{s}}{2 \chi_{o} f_{c, 0} b}\left[\left(f_{s y}-E_{S H} \varepsilon_{s y}\right)(1+\delta)-E_{S H} \varepsilon_{w u}(1+\delta)\right]-\sqrt{\left\{\frac{A_{s}}{2 \chi_{o} f_{c, 0} b}\left[\left(f_{s y}-E_{S H} \varepsilon_{s y}\right)(1+\delta)-E_{S H} \varepsilon_{w u}(1+\delta)\right]\right\}^{2}+\frac{E_{S H} \varepsilon_{w u} A_{s} d}{\chi_{0} f_{c, 0} b}(1+\delta \alpha)}$ \\
\hline
\end{tabular}

\section{Materials and methods}

All the tested specimens are made of two glued-laminated beams of Norway spruce wood (Picea abies) with a cross section that is $120 \mathrm{~mm}$ wide, $295 \mathrm{~mm}$ deep. Each beam is $2850 \mathrm{~mm}$ long, and they are connected together at one end with glued-in threaded steel rods so to obtain a beam that is $5700 \mathrm{~mm}$ in length. The holes drilled in the timber had a diameter $4 \mathrm{~mm}$ larger than the one of the rod (the rod diameters were 14, 16 and $20 \mathrm{~mm}$ ). The rods were put inside the holes using a wire guide to center them, and epoxy resin was then injected through $6 \mathrm{~mm}$ diameter holes drilled perpendicularly to each embedment hole, near its ends.

The mechanical characteristics of the wood and the steel used for the samples are described in Table 2. All the presented data derive from specific tests on timber and steel samples, at least 3 for each mechanical characteristic to be determined (Buttazzi [25]). For all the mechanical characteristics both the average value and the coefficient of variation were reported.

All the beams were subjected to two symmetric loads at a relative distance of $1600 \mathrm{~mm}$, applied through a steel beam, and the distance between the supports was $5500 \mathrm{~mm}$ (Fig. 2). The beams were tested by using a displacement hydraulic servo-controlled system.

In monotonic tests, to avoid local crushing of the wood, considering point loads and support reactions, steel plates $(120 \times 120 \times 15 \mathrm{~mm})$ were used, and to allow for free rotation of the beam at the supports, steel cylinders were positioned.

In cyclic tests, as it was necessary to invert the load direction, the glulam beam was connected to the rig steel beam by four steel plates: both steel and timber beams presented two holes where at the end threaded pins were inserted. The pins were stopped by nuts contrasting against the steel plates. The same system of plates was used at the edges of the timber beam to connect it to the steel rig.

On the beam front and back surfaces, two other steel girders were fixed to the steel frame to prevent lateral instability displace- ments of the tested timber beam. Appropriate PTFE (polytetrafluoroethylene) friction bearings were interposed between the girders and the timber beam so to make negligible the friction when the beam deforms vertically. The complete setup for cyclic tests is illustrated in Fig. 2. For monotonic tests the only difference concerns the supports, which were as described above.

Twelve linear variable displacement transducers (LVDTs) were arranged to survey the main displacement parameters. The instrumentation arrangement is illustrated in detail in Fig. 3.

In particular, two couples of LVDTs $\left(\mathrm{T}_{1}-\mathrm{T}_{2}, \mathrm{~T}_{3}-\mathrm{T}_{5}\right)$ were placed in the mid-span section, one on the front side and the other on the backside of the beam, close to the top and bottom of the beam, respectively. These data were used to calculate the rotation in the joint section. The global rotation was masured between two sections at a relative distance of $1200 \mathrm{~mm}$ by using two inductive transducers $\left(T_{5}-T_{6}\right)$. Two other inductive transducers $\left(T_{7}-T_{8}\right)$ were used to survey the mid-span deflection of the beam. Four more gauges $\left(T_{9}-T_{10}, T_{11}-T_{12}\right)$ were used to measure the rotation at the supports. These values, as well as the values obtained from transducers $T_{5}-T_{6}$ and $T_{7}-T_{8}$, were used to check the reliability of the rotation measured in the joint section. All of the transducers had a sensitivity of $0.002 \mathrm{~mm}$, except those used to measure the midspan deflection $\left(\mathrm{T}_{7}-\mathrm{T}_{8}\right)$ with a sensitivity of $0.02 \mathrm{~mm}$.

For monotonic tests, the vertical displacement was varied at the speed of $0.2 \mathrm{~mm} / \mathrm{s}$ up to reaching the collapse of the joint. The speed was calibrated assuming that the test duration has to be approximately $300 \mathrm{~s}$. The cyclic loading procedure consisted in the variation of the vertical displacements according to the protocol given by EN 12512 [30]. So, firstly the displacement corresponding to the start of the "conventional yielding" was estimated $\left(v_{y, e s t}\right)$ and then the sequence described in Table 3 and Fig. 4 was applied. The effective yielding displacement $\left(v_{y, e f f}\right)$ was deduced during the test. Also cyclic tests carried out were quasistatic and the speed was calibrated as for monotonic tests.

The load was surveyed through a loading cell (accuracy $\pm 0.25 \%$ of reading) and the data acquisition (load and displacements) was

Table 2

Mechanical material properties.

\begin{tabular}{|c|c|c|c|c|}
\hline Materials & Mechanical characteristics & 1st Group & 2nd Group & 3rd Group \\
\hline Wood & $\begin{array}{l}\text { Strength Grade } \\
\mathrm{f}_{\mathrm{m}}[\mathrm{MPa}] \\
\mathrm{f}_{\mathrm{c}, 0}[\mathrm{MPa}] \\
\mathrm{f}_{\mathrm{t}, 0}[\mathrm{MPa}] \\
\mathrm{E}_{\mathrm{c}, 0}[\mathrm{MPa}]\end{array}$ & $\begin{array}{l}\text { GL } 24 \text { h } \\
42.3(9.2 \%) \\
36.8(9.7 \%) \\
29.2(15.4 \%) \\
9856(13.6 \%)\end{array}$ & $\begin{array}{l}\text { GL } 24 \mathrm{~h} \\
46.4(8.3 \%) \\
44.2(10.4 \%) \\
30.0(13.3 \%) \\
12993(16.4 \%)\end{array}$ & $\begin{array}{l}\text { GL } 24 \mathrm{~h} \\
46.4(8.3 \%) \\
44.2(10.4 \%) \\
30.0(13.3 \%) \\
12993(16.4 \%)\end{array}$ \\
\hline Steel & $\begin{array}{l}\text { Steel type } \\
\mathrm{f}_{\mathrm{ys}}[\mathrm{MPa}] \\
\mathrm{f}_{\mathrm{ts}}[\mathrm{MPa}]\end{array}$ & $\begin{array}{l}\text { C40 } \\
607(2.9 \%) \\
707(3.5 \%)\end{array}$ & $\begin{array}{l}\text { S355 } \\
398(6.0 \%) \\
543(4.8 \%)\end{array}$ & $\begin{array}{l}\text { S275 } \\
316(4.0 \%) \\
457(2.0 \%)\end{array}$ \\
\hline
\end{tabular}

a EN 10083-2:2006 [28].

b EN 10025-2:2004 [29]. 


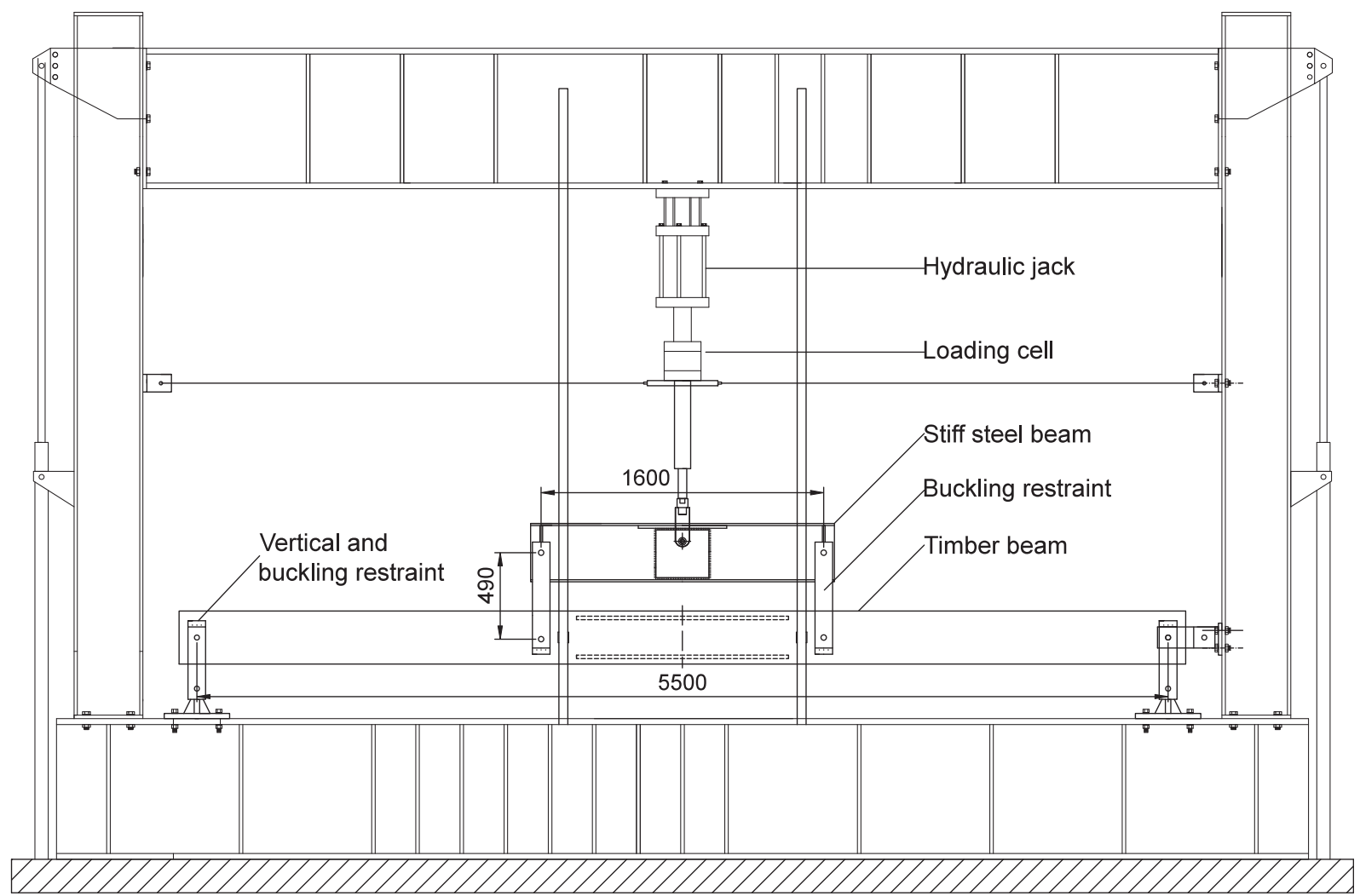

Fig. 2. Setup for tests on beam joints.

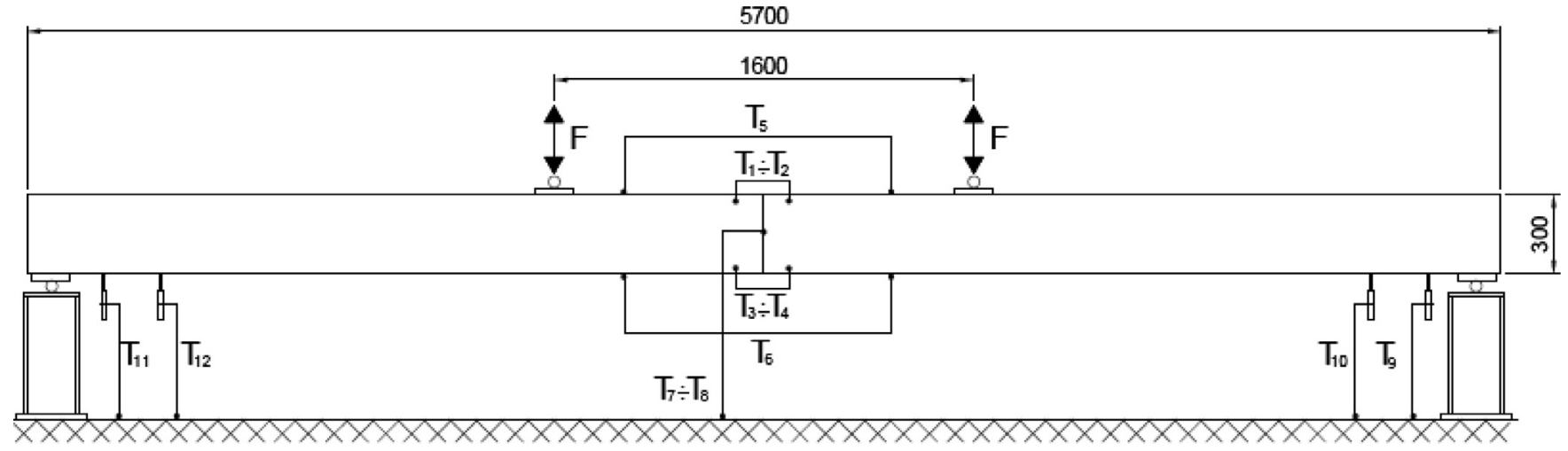

Fig. 3. Arrangement of electrical transducers used for bending tests.

Table 3

Cycles of applied displacement.

\begin{tabular}{ll}
\hline Displacement & Number of cycles \\
\hline $0.25 v_{y, \text { est }}$ & 1 \\
$0.5 v_{y, \text { est }}$ & 1 \\
$0.75 v_{y, \text { est }}$ & 3 \\
$v_{y, \text { est }}$ & 3 \\
$v_{y, \text { eff }}$ & 3 \\
$1.5 v_{y, \text { eff }}$ & 3 \\
$2 v_{y, \text { eff }}$ & 3 \\
$3 v_{y, \text { eff }}$ & 3 \\
\hline
\end{tabular}

carried out by an electronic unit governed with a computer. All data were registered and currently displayed on the monitor, so to allow a constant check of the data. At the beginning of each test,

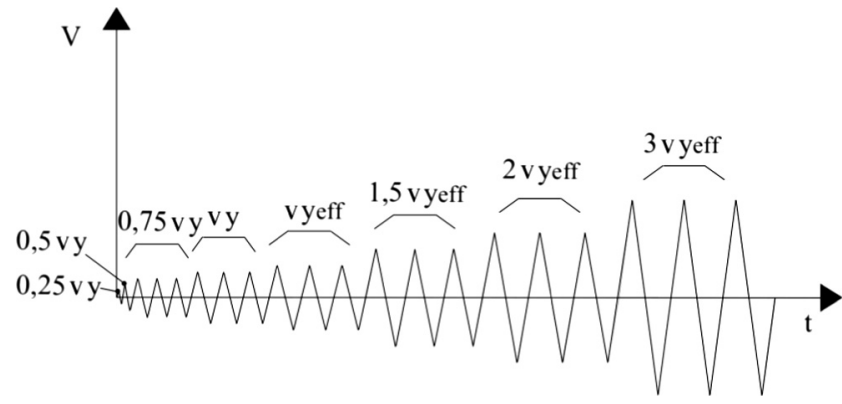

Fig. 4. Cycles of applied displacements.

the wood moisture content was surveyed by means of an electric moisture meter (accuracy 0.5\%). 


\section{Experimental tests}

\subsection{Monotonic bending tests}

Sixteen beam specimens were arranged and subjected to monotonic bending tests with the purpose to check the behavior of the joints section. Three different grades for the steel of rods (Table 2) were considered and the effect of screws arranged perpendicular to the rods in the joint area was also analyzed.

\subsubsection{Specimens}

The tested specimens are identified by an acronym of two letters, followed by two numbers separated by a hyphen. The first two letters are related to rod arrangement: TD for sections with one horizontal layer of two bars, TV for a vertical layer of two bars, TT for a triangular arrangement, and TQ for two horizontal layers of two bars each. The first number identifies the rod diameter in millimeters, and the other indicates the lateral edge distance. Two specimens (TC16-32 and TC16-40) were provided with screwed bolts ( $8 \mathrm{~mm}$ diameter, $140 \mathrm{~mm}$ length) that were placed at the beam jointed end perpendicular to the longitudinal axis, with the aim to prevent splitting of the wood along the rods. The different types of cross sections of the tested beams are illustrated in Fig. 5. In the figure the dimensions of the cross section and the position of the rods inside the timber element are reported.

The edge distance was assumed equal to twice the bar diameter so to arrange a steel cross section adequate to guarantee a bending resistance in the joint section not lower than $60 \%$ that of the actual whole cross section. Different distributions of the bars were considered to check also the effect of rods distributed in one or two layers, using then large $(20 \mathrm{~mm})$ or small bar diameters $(14 \mathrm{~mm})$.

The arrangement of the specimens was calculated using the design relationships presented in Section 2. In eight specimens the steel rods were of steel grade C40, a hardened and tempered steel, in the other samples a mild steel was used: in four specimens the steel was S355 and in other four specimens the steel was S275 (Table 2). The bond development length was derived assuming that the pull out resistance of the rod (Eqs. (1) and (2)), multiplied by the splitting reduction factor (Eq. (3)), is equal to the minimum of both the tensile resistance of timber effective area and the tensile resistance of the steel rod. The values obtained range approximately from 27 to 32 times the bar diameter. In the tests, the embedment length was assumed equal to 30 times the bar diameter for all specimens, that is a value quite close to the bond development length calculated.
In Tables 4 and 5 some characteristic data of each specimen and the calculated glued-in rod resistances $\left(F_{\text {pull }}, F_{\text {split }}, F_{\text {tens }}, F_{s y}, F_{s t}\right)$, necessary to determine the resisting moment of the joint cross section, are summarized. An average value of $460 \mathrm{~kg} / \mathrm{m}^{3}$ was taken from the material test results for the specific mass of timber. The effective area around the rod was evaluated for the sections of the tested specimens according to Fig. 6.

For the considered cases $\left(a, b_{1}, b_{2}, c, d\right)$ the resisting moments calculated with the relationships presented in Section 2 are reported. In the last row of the Tables, the ratio between the moment capacity of the jointed section and that of the gross section are also reported. As it can be seen, with the exception of few cases, the bending resistance of jointed section is greater than $60 \%$ that of the gross section.

It can be noted that the expected joint failure for specimens arranged with high tensile strength steel rods (C40) is brittle and due mainly to tensile failure of timber in the effective area around the rod or to longitudinal splitting. In specimens TC16-32/1 and TC16-40/1 the expected collapse is due to tensile failure of the rods, but the resisting moment is quite close to that associated to splitting failure. Also most of the specimens of the second group (steel grade S355) evidence an expected collapse due to the tensile failure of the timber in the effective area around the bar. On the contrary, the expected collapse of specimens arranged with S275 steel grade rods is due to failure of timber in compression. The resisting moment is, however, very close to that associated to the tensile failure of the rods.

\subsubsection{Results}

The results are summarized in Table 6, where in addition to the moisture content of the wood at the time of testing, some important information concerning both the elastic and ultimate limit state is reported. The moisture content is the average value of 10-15 readings along the beam. For the elastic limit state, the yielding moment (defined according to EN 12512 [30]) and the corresponding yielding rotation are presented. For the collapse condition, the ultimate moment, the corresponding mid-span deflection, the joint rotation and the global rotation, evaluated between two sections at a relative distance of $1200 \mathrm{~mm}$, are indicated. The rotation ductility factor is also calculated.

The beams are divided into three groups based on the mechanical properties of the materials used for the joints.

In Fig. 7 Moment-Rotation diagrams for the tested beams are reported. It is evident how much the behavior changes by using steel of different mechanical characteristics.

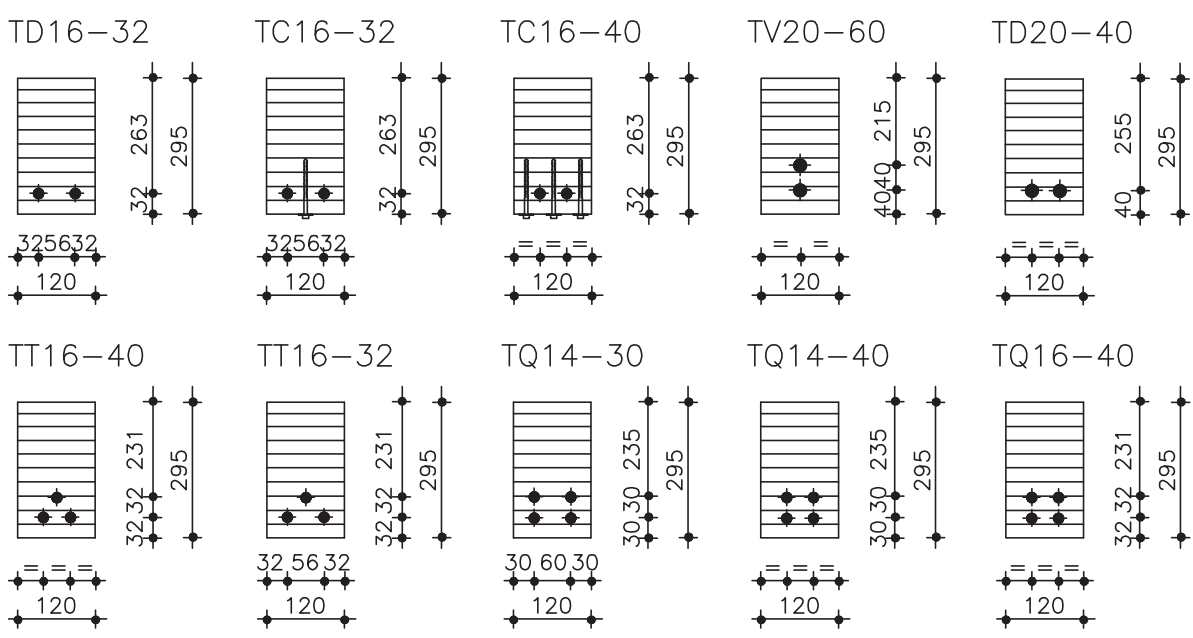

Fig. 5. Geometric characteristics of the beams and cross section details. 
Table 4

Bending capacity of the first group of specimens subjected to monotonic tests.

\begin{tabular}{|c|c|c|c|c|c|c|c|c|c|}
\hline $\begin{array}{l}\text { Specimen } \\
\text { identification }\end{array}$ & & TQ14-40/1 & TQ14-30/1 & TD16-32/1 & TT16-40/1 & TC16-32/1 & TC16-40/1 & TD20-40/1 & TV20-60/1 \\
\hline$f_{v m}$ & $\mathrm{MPa}$ & 3.98 & 3.98 & 3.72 & 3.72 & 3.72 & 3.72 & 3.29 & 3.29 \\
\hline$k_{s}$ & & 0.786 & 0.786 & 0.925 & 0.775 & 1.000 & 1.000 & 0.925 & 0.775 \\
\hline$A_{e f f}$ & $\mathrm{~mm}^{2}$ & 2446 & 2446 & 3526 & 2566 & 7486 & 7486 & 4348 & 4348 \\
\hline$F_{\text {pull }}$ & $\mathrm{N}$ & 91960 & 91960 & 112054 & 112054 & 112054 & 112054 & 149057 & 149057 \\
\hline$F_{\text {split }}$ & $\mathrm{N}$ & 72254 & 72254 & 103650 & 86842 & 112054 & 112054 & 137878 & 115519 \\
\hline$F_{\text {tens }}$ & $\mathrm{N}$ & 71410 & 71410 & 102955 & 74923 & 218587 & 218587 & 126950 & 126950 \\
\hline$F_{u}$ & $\mathrm{~N}$ & 71410 & 71410 & 102955 & 74923 & 112054 & 112054 & 126950 & 115519 \\
\hline$F_{s y}$ & $\mathrm{~N}$ & 69805 & 69805 & 95195 & 95195 & 95195 & 95195 & 148742 & 148742 \\
\hline$F_{s t}$ & $\mathrm{~N}$ & 81305 & 81305 & 110878 & 110878 & 110878 & 110878 & 173246 & 173246 \\
\hline$M_{u, i n t}$ & $\mathrm{Nm}$ & 73623 & 73623 & 73623 & 73623 & 73623 & 73623 & 73623 & 73623 \\
\hline$F_{u}<F_{s y}$ & \multicolumn{9}{|c|}{ with linear compression timber stresses and linear steel rods } \\
\hline$M_{u, a}$ & $\mathrm{Nm}$ & 53212 & 53212 & 46194 & 43620 & 50277 & 50277 & 53540 & 42762 \\
\hline$F_{s y}<F_{u}<F_{s t}$ & \multicolumn{9}{|c|}{ with plastic timber in compression and rods one or both layers yielded } \\
\hline$M_{u, b}$ & $\mathrm{Nm}$ & 62015 & 62015 & 49354 & - & 53254 & 53254 & - & - \\
\hline$F_{u}>F_{y s}$ & \multicolumn{9}{|c|}{ with plastic timber in compression and rods failure } \\
\hline$M_{u, c}$ & $\mathrm{Nm}$ & 68620 & 68620 & 52754 & 70896 & 52754 & 52754 & 74762 & 72270 \\
\hline$F_{u}>F_{y s}$ & \multicolumn{9}{|c|}{ with plastic timber in compression and timber compression failure } \\
\hline$M_{u, d}$ & $\mathrm{Nm}$ & 68340 & 68340 & 56090 & 70251 & 56090 & 56090 & 73169 & 71342 \\
\hline \multicolumn{10}{|l|}{ Capacity } \\
\hline & $\mathrm{Nm}$ & 62015 & 62015 & 49354 & 43620 & 52754 & 52754 & 53540 & 42762 \\
\hline$M_{u} / M_{u, i n t}$ & & 0.84 & 0.84 & 0.67 & 0.59 & 0.72 & 0.72 & 0.73 & 0.58 \\
\hline
\end{tabular}

Table 5

Bending capacity of second and third group of specimens subjected to monotonic tests.

\begin{tabular}{|c|c|c|c|c|c|c|c|c|c|}
\hline $\begin{array}{l}\text { Specimen } \\
\text { identification }\end{array}$ & & TD20-40/2 & TT16-40/2 & TT16-32/2 & TQ16-32/2 & TD20-40/3 & TQ14-30/3 & TT16-32/3 & TQ16-32/3 \\
\hline$f_{v m}$ & $\mathrm{MPa}$ & 3.29 & 3.72 & 3.72 & 3.72 & 3.29 & 3.98 & 3.72 & 3.72 \\
\hline$k_{s}$ & & 0.925 & 0.775 & 0.775 & 0.775 & 0.925 & 0.786 & 0.775 & 0.775 \\
\hline$A_{e f f}$ & $\mathrm{~mm}^{2}$ & 4348 & 2566 & 2566 & 2494 & 4348 & 2446 & 2566 & 2566 \\
\hline$F_{\text {pull }}$ & $\mathrm{N}$ & 149057 & 112054 & 112054 & 112054 & 149057 & 91960 & 112054 & 112054 \\
\hline$F_{\text {split }}$ & $\mathrm{N}$ & 137878 & 86842 & 86842 & 86842 & 137878 & 72254 & 86842 & 86842 \\
\hline$F_{\text {tens }}$ & $\mathrm{N}$ & 130428 & 76975 & 76975 & 74815 & 130428 & 73366 & 76975 & 76975 \\
\hline$F_{u}$ & $\mathrm{~N}$ & 130428 & 76975 & 76975 & 74815 & 130428 & 72254 & 76975 & 76975 \\
\hline$F_{s y}$ & $\mathrm{~N}$ & 97528 & 62418 & 62418 & 62418 & 77434 & 36340 & 49558 & 49558 \\
\hline$F_{s t}$ & $\mathrm{~N}$ & 133059 & 85158 & 85158 & 85158 & 111985 & 52555 & 71671 & 71671 \\
\hline$M_{u, i n t}$ & $\mathrm{Nm}$ & 80759 & 80759 & 80759 & 80759 & 80759 & 80759 & 80759 & 80759 \\
\hline$F_{u}<F_{s y}$ & \multicolumn{9}{|c|}{ with linear compression timber stresses and linear steel rods } \\
\hline$M_{u, a}$ & $\mathrm{Nm}$ & 55302 & 45138 & 45138 & 54405 & 55302 & 54271 & 45138 & 54803 \\
\hline$F_{s y}<F_{u}<F_{s t}$ & \multicolumn{9}{|c|}{ with plastic timber in compression and rods one or both layers yielded } \\
\hline$M_{u, b}$ & $\mathrm{Nm}$ & 60104 & 52817 & 52817 & 65676 & 60104 & 62410 & 52450 & 65518 \\
\hline$F_{u}>F_{y s}$ & \multicolumn{9}{|c|}{ with plastic timber in compression and rods failure } \\
\hline$M_{u, c}$ & $\mathrm{Nm}$ & 61184 & 57649 & 57649 & 72949 & 52384 & 47500 & 49257 & 61775 \\
\hline$F_{u}>F_{y s}$ & \multicolumn{9}{|c|}{ with plastic timber in compression and timber compression failure } \\
\hline$M_{u, d}$ & $\mathrm{Nm}$ & 51969 & 49721 & 49721 & 61623 & 44493 & 41406 & 42609 & 51712 \\
\hline \multicolumn{10}{|l|}{ Capacity } \\
\hline$M_{u}$ & $\mathrm{Nm}$ & 51969 & 49721 & 49721 & 61623 & 44493 & 41406 & 42609 & 51712 \\
\hline$M_{u} / M_{u, i n t}$ & & 0.64 & 0.62 & 0.62 & 0.76 & 0.55 & 0.51 & 0.53 & 0.64 \\
\hline
\end{tabular}
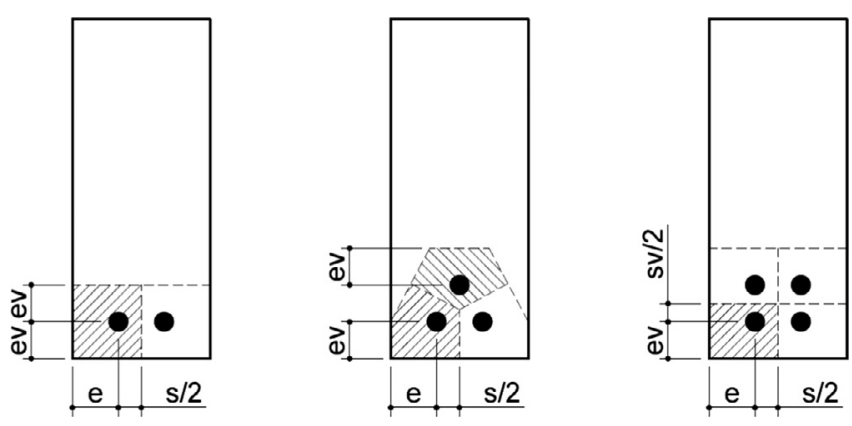

Fig. 6. Schematization of the effective area around the steel rods.
The beams of the first group demonstrated a brittle failure, characterized by tensile rupture of the timber surrounding the rod (Fig. 7a and Fig. 8a). The values of ductility obtained are, in fact, very low and very little differences were noted among specimens with diverse arrangement of the rods. The beam with the joint made with a lower steel area TD16-32/1, approximately 2/3 times that of the other beams, evidenced a lower moment capacity and an appreciably higher ductility (Fig. 7b - Table 6). The joint collapse was due to failure in tension of the timber surrounding rods and it was quite similar to that illustrated in Fig. 8a. The larger ductility was due to the more pronounced plasticization of the steel rods. Specimens TC16-32/1 and TD16-40/1 have the same arrangement as specimen TD16-32/1 but some screws perpendicular to the rods were added. The results in terms of moment-rotation do not show appreciable differences among the three curves (Fig. 7b). 
Table 6

Experimental results of monotonic bending tests.

\begin{tabular}{|c|c|c|c|c|c|c|c|c|}
\hline \multirow{2}{*}{$\begin{array}{l}\text { Specimen } \\
\text { identification }\end{array}$} & \multirow{2}{*}{$\begin{array}{l}\text { Moisture } \\
\text { content } \\
(\%)\end{array}$} & \multicolumn{2}{|c|}{ Elastic limit state } & \multicolumn{5}{|c|}{ Plastic behaviour - Maximum values } \\
\hline & & $\begin{array}{l}\text { Yielding } \\
\text { moment } \\
(\mathrm{kNm})\end{array}$ & $\begin{array}{l}\text { Yielding rotation } \varphi_{\mathrm{y}} \\
\text { (rad) }\end{array}$ & $\begin{array}{l}\text { Ultimate } \\
\text { moment } \\
(\mathrm{kNm})\end{array}$ & $\begin{array}{l}\text { Deflection } \\
(\mathrm{mm})\end{array}$ & $\begin{array}{l}\text { Rotation } \\
\varphi_{\mathrm{u}} \\
\text { (rad) }\end{array}$ & $\begin{array}{l}\text { Ductility } \\
\text { factor } \\
\varphi_{\mathrm{u}} / \varphi_{\mathrm{y}}\end{array}$ & $\begin{array}{l}\text { Global } \\
\text { rotation } \\
\text { (rad) }\end{array}$ \\
\hline \multicolumn{9}{|c|}{ 1st Group/C40 steel bars } \\
\hline TQ14-40/1 & 9.5 & 41.2 & 0.0044 & 41.2 & 44.9 & 0.0051 & 1.1 & 0.0170 \\
\hline TQ14-30/1 & 9.2 & 49.2 & 0.0042 & 59.0 & 68.4 & 0.0073 & 1.7 & 0.0208 \\
\hline TD16-32/1 & 9.9 & 40.5 & 0.0055 & 49.1 & 69.3 & 0.0201 & 3.6 & 0.0312 \\
\hline TT16-40/1 & 8.9 & 43.6 & 0.0052 & 43.6 & 45.1 & 0.0058 & 1.1 & 0.0194 \\
\hline TC16-32/1 & 9.7 & 40.9 & 0.0063 & 47.1 & 69.7 & 0.0187 & 2.9 & 0.0311 \\
\hline TC16-40/1 & 10.4 & 43.3 & 0.0069 & 51.8 & 75.9 & 0.0197 & 2.8 & 0.0353 \\
\hline TD20-40/1 & 9.1 & 45.8 & 0.0053 & 55.8 & 64.7 & 0.0107 & 2.0 & 0.0249 \\
\hline TV20-60/1 & 10.0 & 44.2 & 0.0057 & 47.9 & 59.4 & 0.0114 & 2.0 & 0.0228 \\
\hline \multicolumn{9}{|c|}{ 2nd Group/S355 steel bars } \\
\hline TT16-32/2 & 11.1 & 36.4 & 0.0059 & 44.9 & 91.0 & 0.0343 & 6.6 & 0.0469 \\
\hline TT16-40/2 & 11.6 & 37.9 & 0.0048 & 43.0 & 55.8 & 0.0117 & 2.4 & 0.0187 \\
\hline TQ16-32/2 & 11.9 & 43.3 & 0.0053 & 52.7 & 85.6 & 0.0149 & 2.8 & 0.0262 \\
\hline TD20-40/2 & 11.4 & 33.9 & 0.0045 & 41.2 & 86.9 & 0.0277 & 6.2 & 0.0391 \\
\hline \multicolumn{9}{|c|}{ 3rd Group/S275 steel bars } \\
\hline TQ14-30/3 & 11.7 & 39.8 & 0.0037 & 45.9 & 296.0 & 0.1810 & 48.9 & 0.1930 \\
\hline TT16-32/3 & 10.8 & 36.5 & 0.0039 & 43.6 & 137.0 & 0.0622 & 16.0 & 0.0757 \\
\hline TQ16-32/3 & 11.2 & 43.0 & 0.0068 & 47.4 & 258.7 & 0.1513 & 22.2 & 0.1635 \\
\hline TD20-40/3 & 11.4 & 38.1 & 0.0039 & 44.8 & 236.7 & 0.1346 & 34.5 & 0.1481 \\
\hline
\end{tabular}
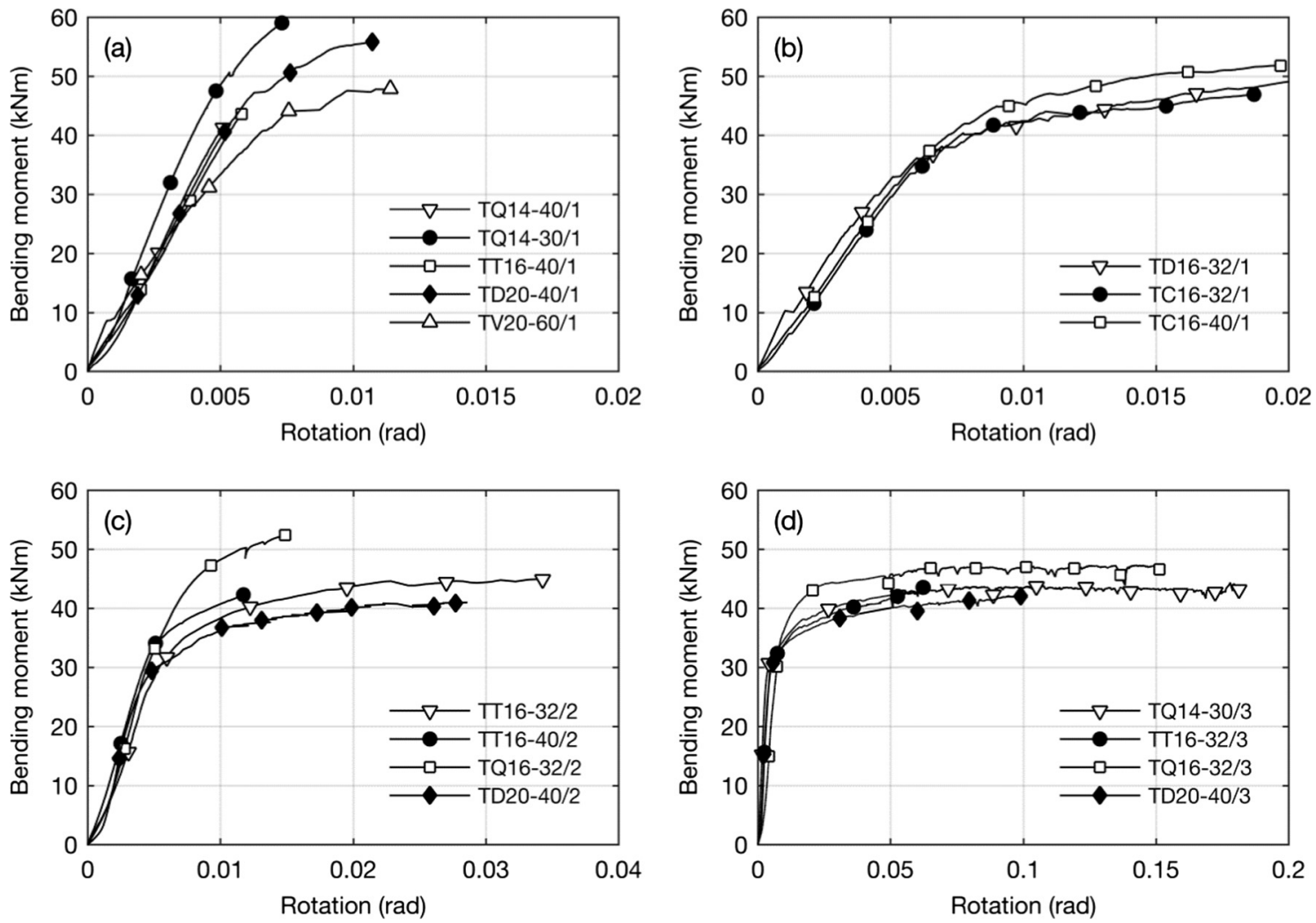

Fig. 7. Moment-rotation diagrams for tested specimens.

So, the application of these screws seems not to increase appreciably the joint effectiveness as it prevents wood splitting only in the intercepted fibers (horizontal splitting), but the formation of longitudinal vertical splitting cracks (Fig. 8b) is not avoided and the sudden drop of the resistance occurred quite early.

The joints of the specimens of the second group were built with rods made of a steel with a lower yielding stress with respect to the one used in the first group: brittle failure still occurred (Figs. 8c,d), but some limited ductility is noted (Fig. 7c). All specimens col- lapsed due to failure in tension of the part of section surrounding the rods (effective area). Moreover the tensile rupture was anticipated by some defects in the timber close to the end of steel rods: group of knots (Fig. 8c), finger joint of one layer of boards (Fig. 8d).

In the beams of the third group, mild steel rods were used, and the joints presented large rotations before collapse, with a significant plastic branch (Fig. 7d and Fig. 8e). The values of ductility obtained are very high in comparison with those of the other two groups. The collapse of the joint section was mainly due to fail- 


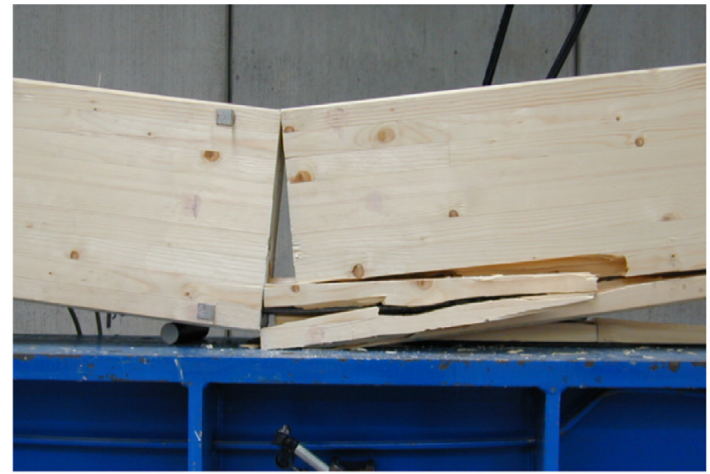

(a)

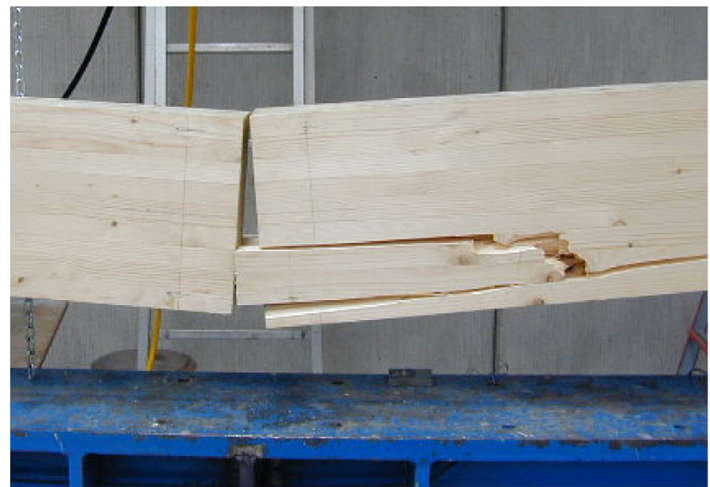

(c)

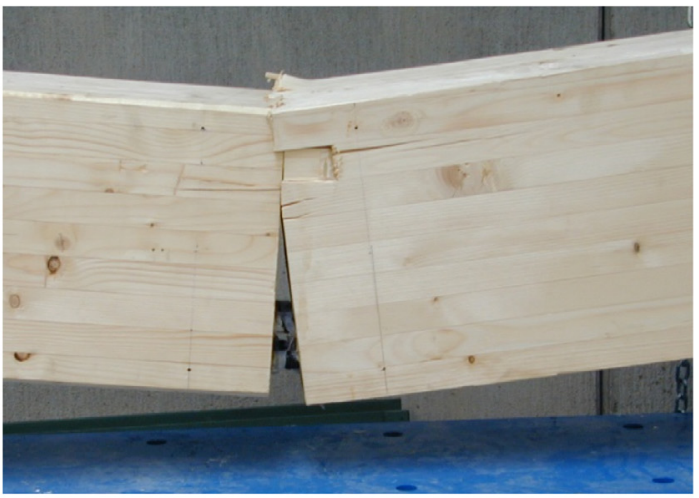

(e)

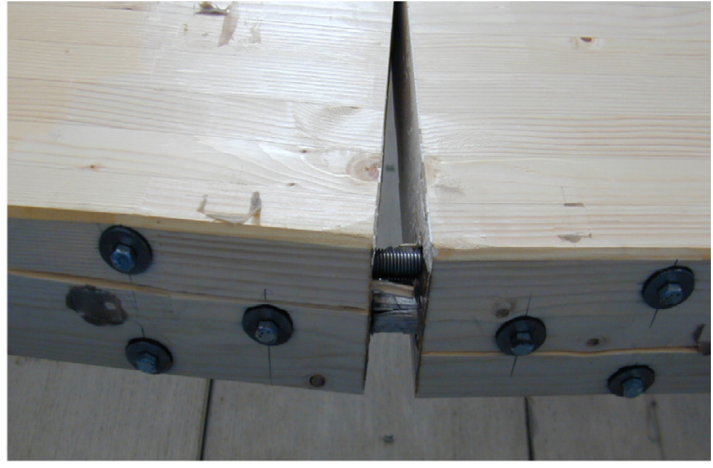

(b)

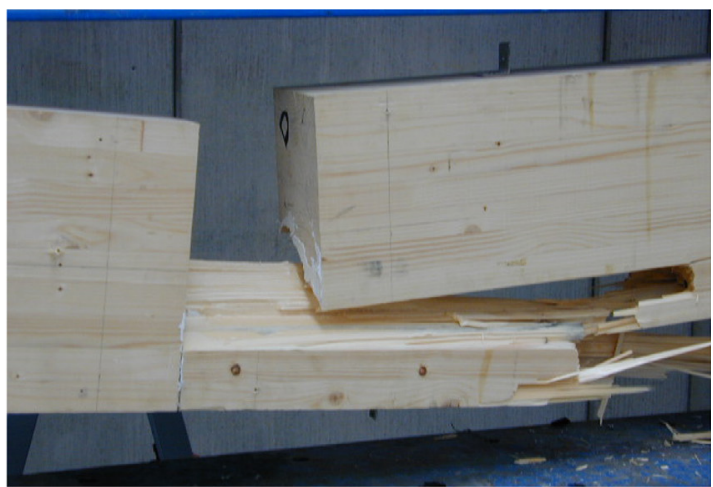

(d)

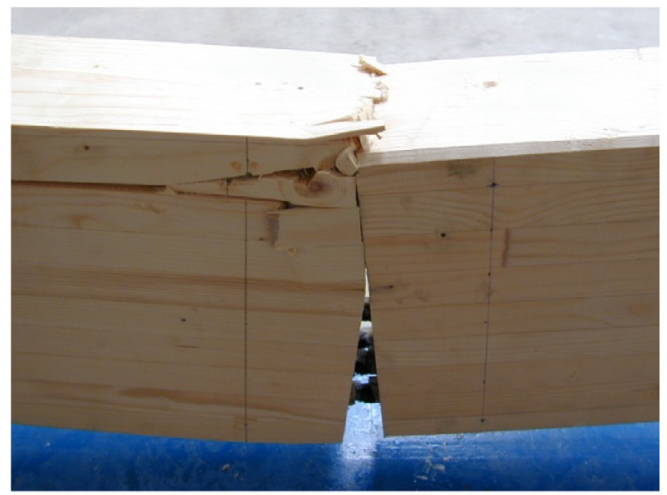

(f)

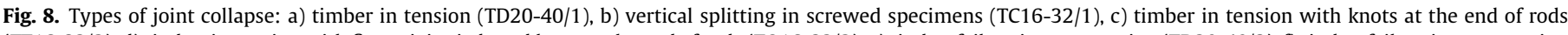

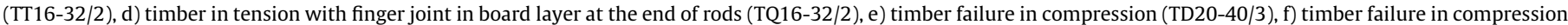
(TQ16-32/3).

ure in compression of timber but after large plastic deformation of the steel rods (Figs. 8e,f).

\subsection{Cyclic bending tests}

Four beam specimens with symmetrical distribution of steel rods in the joint section were submitted to cyclic bending tests in order to check the performances in terms of ductility and energy dissipation. In all specimens the low-yielding steel grade (S275) was used for the rods (Table 2) and no screws perpendicular to the rods in the joint area were arranged.

\subsubsection{Specimens}

The specimens tested under cyclic loads had exactly the same geometric features as those subjected to monotonic bending tests: the joint arrangements that developed the best ductility results under monotonic loads were used to perform cyclic tests, with the difference that the steel rods used to build the glued joint were symmetrically placed at the top and bottom of the section (Fig. 9). Rods with $20 \mathrm{~mm}$ and $16 \mathrm{~mm}$ diameter were used. The edge distance and the distance between the rods are indicated in Fig. 9b. As the edge distances used in the monotonic tests allowed ductile behavior, no changes were made for the cyclic tests. The four tested beams were divided into two groups with different joint geometry.

The beams were identified by an acronym, similar to those used in the monotonic tests. The first two letters were related to the rod arrangement, TD for one horizontal layer of two rods and TQ for two horizontal layers of two rods, while the third letter, D, indicated that the section was doubly reinforced. The first number was related to the rod diameter and the second to the number of the beam in each of the two groups. For each group, two beams 


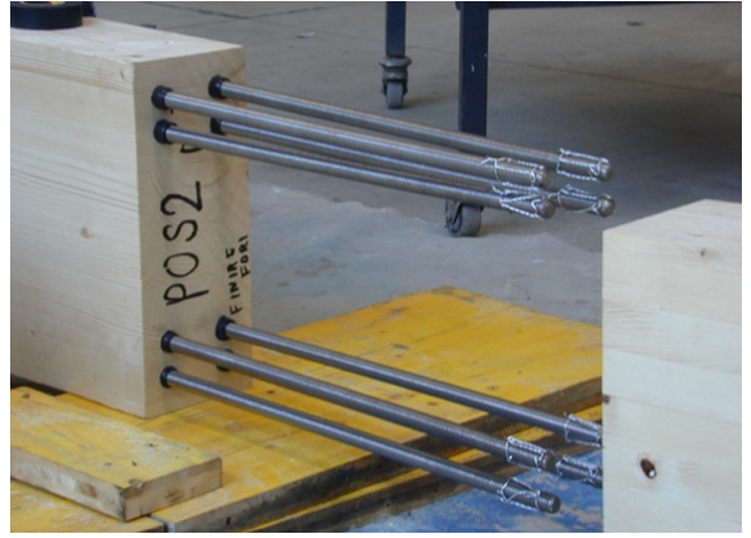

(a)
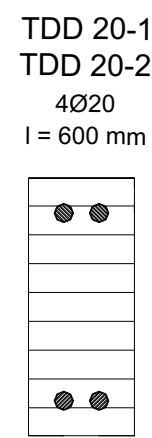

$40,40,40$

120
TQD 14-1

TQD 14-2

$8 \varnothing 14$

$\mathrm{I}=420 \mathrm{~mm}$
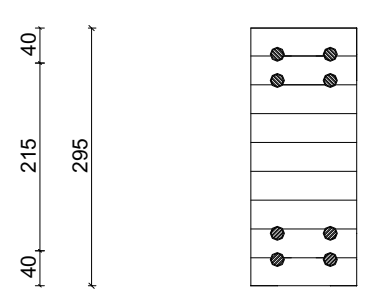

$30,60,30$

120

(b)

Fig. 9. Joint section details: a) view, b) main dimensions (in mm).

with the same characteristics were tested. The rods were made of S275 steel, with the characteristics presented in Table 2, because joints arranged with this steel grade showed the best performance and the highest values of ductility in the monotonic tests.

\subsubsection{Results}

The results of the cyclic tests performed on the beams are summarized in Tables 7 and 8. In the first one, in addition to the wood moisture content at testing, the experimental values of the bending moment and central and global rotation for the positive and negative cycle branches, corresponding to the "conventional yielding" (EN 12512 [30]), are presented. In Table 8, the experimental values of the maximum bending moment and the central and global rotation for positive and negative cycle branches corresponding to the ultimate cyclic limit are given. The data reported are those registered in correspondence with the last three complete cycles of loading and unloading, as suggested in Eurocode 8 [31] for the evaluation of the ductility factor of timber structures.

In Fig. 10, the relationships between the bending moment and the joint rotation are illustrated for the four beams. All the curves have an almost linear path up to a moment of approximately 30$38 \mathrm{kNm}$, which are the same values reached by the beams subjected to the monotonic load.

After the yielding point, at the progression of the cycle number, beams show a different behavior: all the curves display a stiffness reduction, but for TDD 20-1 and TDD 20-2, the cycles are full and round-formed, and for TQD 14-1 and TQD 14-2 there is a pinching effect, as indicated by the reduction of the cycle area. If the rods in tension performed plastic deformations, during the load reversing the whole compression is carried by steel rods, so the section flexural rigidity is only due to steel bars. Moreover, at the progression of the cycle number, when the load is inverted, the rods that were in tension become subjected to compression and, at the increase of the load, if they are not perfectly aligned with the beam axis, they cause lateral pressures on the timber edge leading to the formation of longitudinal splitting cracks (Fig. 11a, b). When splitting occurs, the compressed rods may buckle causing a progressive reduction of the beam stiffness and strength, as reported in the diagrams of Fig. 10. When the two beam parts enter into contact again (compression is supported mainly by timber), the stiffness and strength grow up again until the load inversion or until the beam failure. In Figs. 10b, c, d the almost flat branches followed by a steeper branch when the rotation change direction represent these effects. The section collapse occurred when the glued-in rod joint failed (Fig. 11c).

The relationships in Fig. 10 represent the behavior of the joint in correspondence with the mid-span of the beam: the asymmetry of the curves is due to the possible variation of timber strength and due to the possible misalignment of the rod, that causes the early occurrence of splitting cracks in one part of the beam. The plastic branches in Fig. 10 illustrate that, also under cyclic loads, it is possible to obtain a ductile behavior, even though more limited with respect to beams subjected to monotonic loads. The collapse is different and occurs without reaching failure in tension of the steel rods or crashing in compression of timber.

\subsection{Discussion of the results}

The results of the monotonic bending tests showed that gluedin rod joints can develop ductile behavior and ductile failure only if they are properly designed. As a sort of capacity design, it is necessary to assure for the glued-in rod joint a resistance associated to failure modes $2,3,4,5$ (pull-out, tear out, splitting, tensile strength of the timber block in the effective area) much greater than the rod tensile strength. Only in this way large post yielding deformations can develop in the steel rods and brittle wood collapse mechanisms can be avoided. It is then necessary to use either a low tensile strength for steel of rods or a reduced cross section. But, as the resistance associated to failure modes $2,3,4,5$ depends on the rod diameter and as high strength steel are not ductile, the use of a low

Table 7

Experimental values of the bending moment and rotation for the positive and the negative cycle branch corresponding to "conventional yielding".

\begin{tabular}{|c|c|c|c|c|c|c|c|}
\hline $\begin{array}{l}\text { Specimen } \\
\text { identification }\end{array}$ & $\begin{array}{l}\text { Moisture } \\
\text { content } \\
(\%)\end{array}$ & $\begin{array}{l}\text { Positive } \\
\text { moment } \\
(\mathrm{kNm})\end{array}$ & $\begin{array}{l}\text { Positive } \\
\text { rotation } \\
\text { (rad) }\end{array}$ & $\begin{array}{l}\text { Positive global } \\
\text { rotation } \\
\text { (rad) }\end{array}$ & $\begin{array}{l}\text { Negative } \\
\text { moment } \\
(\mathrm{kNm})\end{array}$ & $\begin{array}{l}\text { Negative } \\
\text { rotation } \\
(\mathrm{rad})\end{array}$ & $\begin{array}{l}\text { Negative global } \\
\text { rotation } \\
\text { (rad) }\end{array}$ \\
\hline TDD 20-1 & & 32.03 & 0.0029 & 0.0098 & -38.36 & -0.0037 & -0.0114 \\
\hline TDD 20-2 & 8.8 & 32.60 & 0.0035 & 0.0106 & -37.38 & -0.0034 & -0.0117 \\
\hline TQD 14-1 & 9.4 & 30.68 & 0.0020 & 0.0086 & -34.79 & -0.0018 & -0.0098 \\
\hline TQD 14-2 & 9.3 & 29.13 & 0.0019 & 0.0079 & -35.71 & -0.0021 & -0.0099 \\
\hline
\end{tabular}


Table 8

Experimental values of the bending moment and rotation for the positive and the negative cycle branch corresponding to ultimate limit state.

\begin{tabular}{|c|c|c|c|c|c|c|}
\hline $\begin{array}{l}\text { Specimen } \\
\text { identification }\end{array}$ & $\begin{array}{l}\text { Positive maximum } \\
\text { moment } \\
(\mathrm{kNm})\end{array}$ & $\begin{array}{l}\text { Positive } \\
\text { rotation } \\
\text { (rad) }\end{array}$ & $\begin{array}{l}\text { Positive global } \\
\text { rotation } \\
\text { (rad) }\end{array}$ & $\begin{array}{l}\text { Negative maximum } \\
\text { moment } \\
(\mathrm{kNm})\end{array}$ & $\begin{array}{l}\text { Negative } \\
\text { rotation } \\
\text { (rad) }\end{array}$ & $\begin{array}{l}\text { Negative global } \\
\text { rotation } \\
\text { (rad) }\end{array}$ \\
\hline TDD 20-1 & 38.29 & 0.0250 & 0.0334 & -42.40 & -0.0213 & -0.0292 \\
\hline TDD 20-2 & 37.62 & 0.0296 & 0.0414 & -44.90 & -0.0182 & -0.0387 \\
\hline TQD 14-1 & 37.61 & 0.0271 & 0.0348 & -43.50 & -0.0122 & -0.0289 \\
\hline TQD 14-2 & 37.85 & 0.0307 & 0.0403 & -42.84 & -0.0126 & -0.0277 \\
\hline
\end{tabular}
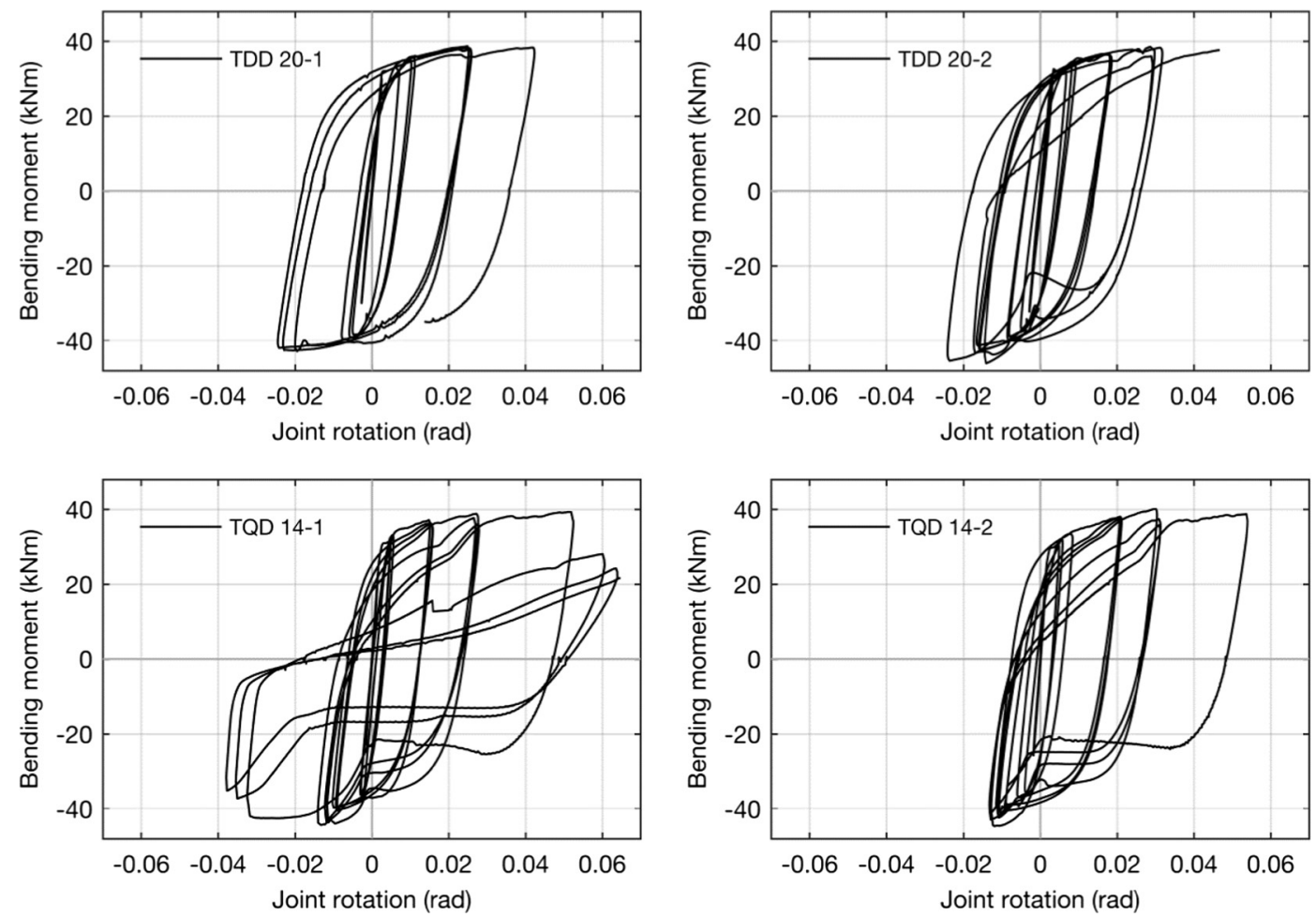

Fig. 10. Moment-joint rotation relationship for the 4 tested beams under cycle load.

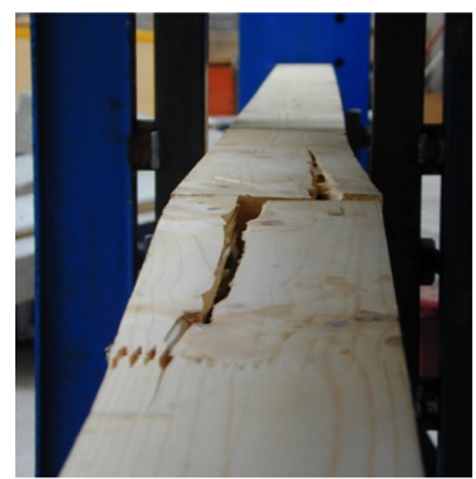

(a)

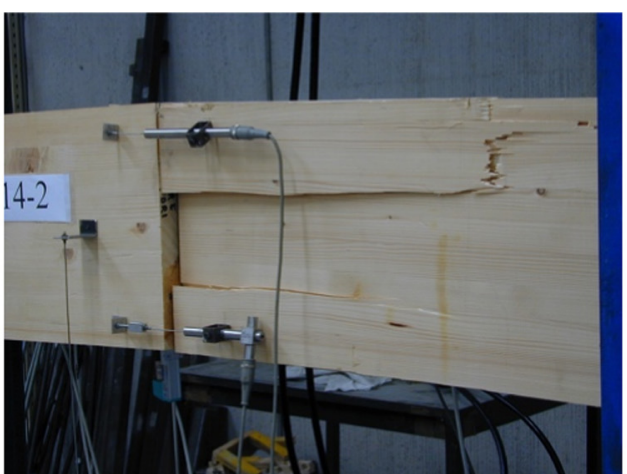

(b)

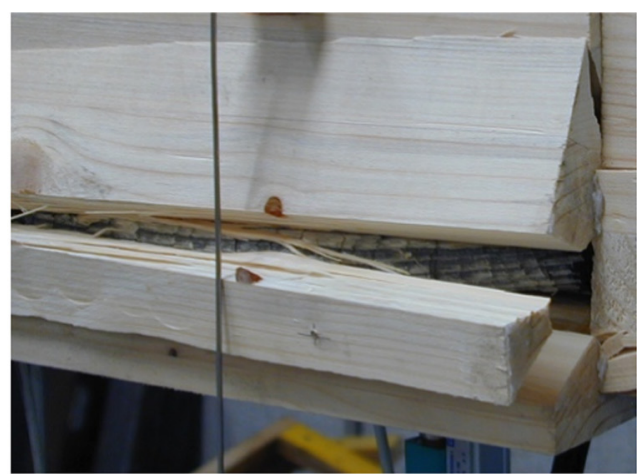

(c)

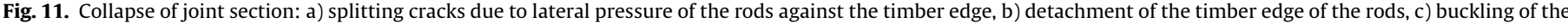
rod

strength steel is the best solution. The results of the monotonic experimental tests allowed to identify that the use of steel S275 for rods permits to reach good ductility for the joint with ultimate strain in the timber in compression and large plastic deformations of steel rods in tension. Very little ductility was noted in joints arranged with S355 steel rods and the collapse was governed by the tensile failure of the timber surrounding the rods (effective area); however this failure occurred after appreciable plastic deformations in the steel. No ductile behavior was noted, with the exception of three cases arranged with C40 small diameter steel rods. The tensile failure of timber surrounding the rods occurred before the yielding or after very little plastic deformation of the rods. 
Table 9

Comparison between analytical prediction and the experimental results obtained with monotonic tests.

\begin{tabular}{|c|c|c|c|c|c|}
\hline \multirow[t]{2}{*}{ Specimen identification } & \multicolumn{2}{|c|}{ Analytical prediction } & \multicolumn{2}{|c|}{ Experimental results } & \multirow[b]{2}{*}{$M_{u} / M_{u, \exp }$} \\
\hline & $M_{u}(\mathrm{kNm})$ & Failure mechanism & $M_{u, \exp }(\mathrm{kNm})$ & Failure mechanism & \\
\hline TQ14-40/1 & 62.0 & Timber in tension & 41.2 & Timber in tension & 1.50 \\
\hline TQ14-30/1 & 62.0 & Timber in tension & 59.0 & Timber in tension & 1.05 \\
\hline TD16-32/1 & 49.4 & Timber in tension & 49.1 & Splitting & 1.00 \\
\hline TT16-40/1 & 42.8 & Timber in tension & 43.6 & Timber in tension & 0.98 \\
\hline TC16-32/1 & 52.8 & Rod failure & 47.1 & Splitting/pull-out & 1.12 \\
\hline TC16-40/1 & 52.8 & Rod failure & 51.8 & Splitting/pull-out & 1.02 \\
\hline TD20-40/1 & 52.8 & Timber in tension & 55.8 & Tensile/splitting & 0.95 \\
\hline TV20-60/1 & 41.9 & Splitting & 47.9 & Splitting & 0.87 \\
\hline TD20-40/2 & 52.7 & Timber in compression & 41.2 & Timber in tension & 1.27 \\
\hline TT16-40/2 & 50.4 & Timber in tension & 43.0 & Timber in tension & 1.17 \\
\hline TT16-32/2 & 50.4 & Timber in tension & 45.0 & Timber in tension & 1.12 \\
\hline TQ16-32/2 & 62.3 & Timber in tension & 52.7 & Timber in tension & 1.18 \\
\hline TD20-40/3 & 45.3 & Timber in compression & 44.8 & Timber in compression & 1.01 \\
\hline TQ14-30/3 & 42.2 & Timber in compression & 45.9 & Timber in compression & 0.92 \\
\hline TT16-32/3 & 43.4 & Timber in compression & 43.6 & Timber in compression & 0.99 \\
\hline TQ16-32/3 & 52.5 & Timber in compression & 47.4 & Timber in compression & 1.10 \\
\hline
\end{tabular}

Table 10

Ductility factors and cycle energy details.

\begin{tabular}{|c|c|c|c|c|c|}
\hline Specimen & $\mu^{+}$ & $\mu^{-}$ & Dissipated energy $E_{d}(\mathrm{~J})$ & Input energy $E_{i}(\mathrm{~J})$ & $E_{d} / E_{i}$ \\
\hline TDD 20-1 & 8.9 & 6.4 & 2604 & 2824 & 0.92 \\
\hline TDD 20-2 & 8.9 & 6.9 & 2844 & 3027 & 0.94 \\
\hline TQD 14-1 & 13.9 & 7.4 & 1986 & 2056 & 0.97 \\
\hline TQD 14-2 & 16.3 & 6.1 & 2006 & 2064 & 0.97 \\
\hline
\end{tabular}

In Table 9, the calculated moment capacity of the joint and the expected failure mechanism are compared with the experimental results, so to check the reliability of the analytical relationships presented in Section 2. For the joints arranged with C40 steel rods, the comparison is good both for moment capacity and collapse mechanism, with the exception of specimen TQ14-40/1. But in this case the collapse in the test was due to the tensile failure of the timber block surrounding the rods and was anticipated by the presence of knots and of a finger joint. In fact, the moment capacity of specimen TQ14-40/1 is considerably lower than that of the similar specimen TQ14-30/1: the former is $41.2 \mathrm{kNm}$, the latter is $59.0 \mathrm{kNm}$. The occurred collapse mechanism of specimens TC16$32 / 1$ and TC16-40/1 concerned in the longitudinal splitting of timber (Fig. 8b) with sudden drop of the joint resistance. The expected collapse mechanism was due to failure of the rods, but the moment capacity due to splitting failure is very close to the one due to failure of the rods.

For the joints arranged with S355 steel for the rods, the prediction of the failure is in good agreement with that occurred in experimental tests. The analytical moment capacity overestimates the experimental values between $12 \%$ to $27 \%$, but this is due to an anticipated failure of the timber block surrounding the rods (effective area), caused by the presence of some defects in the section at the end of the rods: group of knots (Fig. 8c) or finger joint in the board layer (Fig. 8d).

For the joints arranged with S275 steel for rods, a very good prediction of the moment capacity was obtained with the analytical relationships; the predicted failure mechanism is in good agreement with that occurred experimentally.

The values of the ductility factors for the specimens subjected to cyclic tests were calculated with the equations:

$$
\left\{\begin{array}{l}
\mu^{+}=\frac{\varphi_{u}^{+}}{\varphi_{y}^{+}} \\
\mu^{-}=\frac{\varphi_{u}^{-}}{\varphi_{y}^{-}}
\end{array}\right.
$$

in which $\mu^{+}$and $\mu^{-}$are the ductility factors for the positive and negative rotations, respectively, $\varphi_{u}^{+}$is the ultimate rotation in the positive cycle, $\varphi_{u}^{-}$is the ultimate rotation in the negative cycle, $\varphi_{y}^{+}$is the yielding rotation during the positive cycle, $\varphi_{y}^{-}$is the yielding rotation during the negative cycle. The cyclic ultimate rotations were evaluated, according to Eurocode 8, as the extremes of the last cycle where, in three fully reversed repetitions, no more than a $20 \%$ reduction of the resisting moment occurs. The ductility values for the positive and negative branch of the diagram were reported in Table 10. For all specimens tested the ductility factor is always greater than 6 , which correspond to high ductility class (DCH), according to Eurocode 8 [31].

To investigate energy dissipation capacity at a given value of transversal displacement, the input energy was compared to the dissipated hysteretic energy. The input energy has been calculated as the work needed to deform the joint up to the value of the cyclic rotation. It corresponds to the area under the positive and over the negative branches of the hysteretic loop. Similarly the total dissipated hysteretic energy can be calculated as the area included in the hysteretic loop under consideration. In the table the dissipated energy in one cycle (the one corresponding to the ultimate rotation), the input energy in the same cycle and the ratio between dissipated and input energy are also reported. The tested joints evidence a very high dissipation capacity (very wide hysteretic loop).

However, the comparison of the results obtained from cyclic and monotonic tests evidences appreciably lower values of the ductility factors in the cyclic tests. In fact, the ductility developed during cyclic test is between $1 / 3$ and $1 / 4$ that obtained through monotonic tests. This reduction is due to the occurrence of longitudinal splitting in the joint area, caused by the misalignment of the rods with respect to beam axis. In fact, when the rods are deformed plastically, at the inversion of the load all the compression force is transferred through the rods; the misalignment of the rods implies lateral pressures against the timber edge which may cause the 
formation of vertical splitting cracks. Then, the rods not adequately restrained anymore may start to buckle, increasing the lateral pressures against timber and widening the splitting cracks. The crack propagation causes a reduction of the resistance of the glued-in joint and then the collapse.

To improve the ductility performance of the joints under cyclic loading, it is necessary to avoid rigorously the misalignment of the rods which causes formation of longitudinal splitting cracks in the compression zone. Provided that it is not easy to avoid construction tolerances in the arrangement of steel rods, adequate strategies have to be considered to prevent the formation of longitudinal splitting cracks in compression zone as, for example, using transversal screws perpendicular to the rods or using horizontal diagonal screws passing through the joint section. An experimental study aimed to deeply investigate this problem is in progress.

\section{Conclusions}

Glued-in rod joints for glued-laminated beams have great potential to be used as a substitute for traditional mechanical joints because they have high stiffness, there are no clearances between steel and wood, as in bolted joints, and the steel rods are preserved from corrosion by the surrounding timber.

Monotonic bending tests showed that it is possible to obtain a ductile failure of the joint, with a proper choice of the steel rods and of the edge distances. In particular, the tests showed that with high strength steel rods $\left(f_{\mathrm{y}}>600 \mathrm{MPa}\right)$, the collapse is often brittle, whereas with mild steel $\left(\mathrm{f}_{\mathrm{y}}<320 \mathrm{MPa}\right)$, the glued-in rod jointed beams show a very ductile behavior, with values of curvature ductility ranging between 16 and 48. In specimens arranged with high strength steel rods, the application of vertical screws in the joint area did not imply an appreciable increase in both resistance and ductility.

An analytical procedure was presented to design glued-in rod joints in bending, which permits to calculate the moment capacity and the failure mechanism associated. The analytical prediction of the bending resistance of joint section and the failure mechanism are in good agreement with the experimental results.

Cyclic tests were performed on the same type of specimens as for monotonic tests and were arranged with mild steel rods $\left(f_{y} \sim 320 \mathrm{MPa}\right)$. The results of these tests showed that the gluedin rod joint has a good ductility $(\mu>6)$ and a very high dissipation capacity at each cycle after yielding of the rods. On the basis of the request of Eurocode 8 [31] these glued-in rod joints can be assigned to high ductility class (DCH). Differently to monotonic tests, in which the collapse was reached due to crushing of timber in compression, splitting failures occur in the compression zone leading to buckling of the rods.

The splitting cracks occurred due to misalignment of the rods with respect to beam axis. Provided that it is impossible to avoid construction tolerances, adequate strategies have to be used to prevent splitting cracks, as, for example, the use of transversal screws in direction perpendicular to splitting cracks or across the joint section.

\section{Acknowledgements}

The authors wish to thank the Stratex Company S.p.a., Sutrio, Udine, Italy, that kindly supplied the glued-laminated elements for tests, the Resimix S.r.l., Brendola, Vicenza, Italy that offered the epoxy resin, the Friulsider S.p.a., San Giovanni al Natisone, Udine, Italy that offered carpentry elements.

\section{References}

[1] Larsen HJ. Essay 4.3: Glued-in rods. In: Munch-Andersen J, editor. CIB-W18 Timber structures - a review of meeting 1-43. Part 6: Essays; 2011. p. 51-5.

[2] Steiger R, Serrano E, Stepinac M, Rajčić V, O’Neill C, McPolin D, et al Strengthening of timber structures with glued-in rods. Constr Build Mater 2015;97:90-105.

[3] Riberholt H. Glued Bolts in Glulam. Proposal for CIB Code. In: Proceedings of CIB-W18 Meeting 21, Parksville, Canada; September 1988.

[4] Ballerini M, Piazza M, Zanon P. Static and cyclic behaviour of glued joints in timber. Pacific Timber Eng Conf 1994;2:811-7.

[5] Buchanan AH, Deng XJ. Strength of epoxied steel rods in glulam timber. In: International wood engineering conference, Louisiana, USA; 1996, vol. 4. p. 488-95.

[6] Aicher S, Gustafsson PJ, Wolf M. Load displacement and bond strength of glued-in rods in timber influenced by adhesive, wood density, rod slendernes and diameter. In: 1st RILEM Symposium on Timber Engineering, Sweden; 1999. p. 369-78.

[7] Steiger R, Gehri E, Widmann R. Pull-out strength of axially loaded steel rods bonded in glulam parallel to the grain. Mater Struct 2007;40-1:69-78.

[8] Gehri E. Ductile behaviour and group effect of glued-in steel rods. Joints in Timber Structures. In: International RILEM symposium, Stuttgart, Germany; 2001. p. 333-42.

[9] Broughton JG, Hutchinson AR. Pull out behaviour of steel rods bonded into timber. Mater Struct 2001;34-2:100-9.

[10] Tomasi R, Zandonini R, Piazza M, Andreolli M. Ductile end connections for glulam beams. Struct Eng Int 2008:18-3:290-6.

[11] Tlustochowicz G, Serrano E, Steiger R. State-of-the-art review on timber connections with glued-in steel rods. Mater Struct 2011;44-5:997-1020.

[12] Parida G, Johnsson H, Fragiacomo M. Provisions for ductile behaviour of timber-to-steel connections with multiple glued-in rods. J Struct Eng 2013;139-9:1468-77.

[13] Gattesco N, Gubana A. Experimental Study on glulam timber beam joints. In: Proc. $13^{\circ}$ C.T.E. Congress, Pisa, Italy; 2000. p. 403-11 (in Italian).

[14] Gattesco N, Gubana A. Experimental tests on glued joints under axial forces and bending moments. Joints in timber structures. In: International RILEM Symposium, Stuttgart, Germany; 2001. p. 353-62.

[15] Gattesco N, Gubana A. Glued-in bending joints. In: Atti del $14^{\circ}$ Congresso C.T. E., Mantova, Italia; 2002. p. 709-15 (in Italian).

[16] Gattesco N, Gubana A. Performance of glued-in joints of timber members. In: Proc. of the 9th world conference on timber engineering, Portland, OR, USA; 2006.

[17] Gattesco N, Gubana A, Buttazzi M. Pull out strength of bar glued-in-joints. In: Proc. of the 11th world conference on timber engineering, Riva del Garda Italy; 2010.

[18] Stepinac M, Hunger F, Tomasi R, Serrano E, Rajcic V, van de Kuilen JW. Comparison of design rules for glued-in rods and design rule proposal for implementation in European standards. In: Rainer Görlacher, editor. Proceedings of CIB-W18 Meeting 46, Vancouver, Canada; 26-29 August 2013.

[19] Eurocode 5. UNI EN 1995-1-1 Eurocode 5: design of timber structures, Part 11: General - common rules and rules for buildings. Bruxelles, Belgium; 2004

[20] Buchanan AH, Fairweather RH. Seismic design of glulam structures. Bull N Z Natl Soc Earthquake Eng 1993;26-4:415-36.

[21] Andreolli M, Piazza M, Tomasi R, Zandonini R. Ductile moment-resistant steel-timber connections. Proc Instit Civil Eng Struct Build 2011:164 2:65-78.

[22] Fragiacomo M, Batchelar M. Timber frame moment joints with glued-in steel rods. I: Design. J Struct Eng 2012;138-6:789-801.

[23] Yang H, Liu W, Ren X. A component method for moment-resistant glulam beam-column connections with glued-in steel rods. Eng Struct 2016;115:42-54.

[24] Xu BH, Bouchaïr A, Racher P. Analytical study and finite element modelling of timber connections with glued-in rods in bending. Constr Build Mater 2012;34:337-45.

[25] Buttazzi M. Glued-in bar joints in glulam beams [PhD thesis]. University of Trento Doctoral School; 2009. Gattesco N. and Gubana A. Supervisors (in Italian).

[26] Blass HJ, Laskewitz B. Effects of spacing and edge distance on the axial strength of glued in rods. In: Rainer Görlacher, editor. Proceedings of CIB-W18 Meeting 32, Graz, Austria; August 1999.

[27] Eurocode 5 - Part 2. UNI EN 1995-2 Eurocode 5: Design of timber structures, Part 2: Bridges. Bruxelles, Belgium; 2004.

[28] EN 10083-2. Steels for quenching and tempering - Part 2: Technical delivery conditions for non alloy steels. Bruxelles, Belgium; 2006.

[29] EN 10025-2. Hot rolled products of structural steels - Part 2: Technical delivery conditions for non-alloy structural steels. Bruxelles, Belgium; 2004.

[30] EN 12512. Timber structures. Test methods. Cyclic testing of joints made with mechanical fasteners. Bruxelles, Belgium; 2005.

[31] Eurocode 8. UNI EN 1998-1 Eurocode 8: Design of structures for earthquake resistance - Part 1: General rules seismic actions and rules for buildings. Bruxelles, Belgium; 2005. 